\title{
Characteristic Analysis of Grid-side Traction Converter of CRH EMU
}

\author{
Jinhao Wang ${ }^{1, a}$, Min Zhang ${ }^{1}$, Huijie $\mathrm{Du}^{1}$, Shengwen $\mathrm{Li}^{1}$, Yaqi Wang ${ }^{2, \mathrm{~b}}$ and \\ Tingdong Zhou ${ }^{2, \mathrm{c}}$ \\ ${ }^{1}$ State Grid Shanxi Electric Power Research Institute, Taiyuan 030001, China \\ ${ }^{2}$ State Key Laboratory of Alternate Electrical Power System with Renewable Energy Sources, North \\ China Electric Power University, Beijing 102206, China \\ a7wjh@163.com, ${ }^{b} 1527280093 @ q q . c o m,{ }^{c}$ zhoutingdong502@163.com
}

Keywords: CRH EMU; Grid-side traction converter; Characteristic analysis; Two-level; Three-level

\begin{abstract}
This paper studied characteristic of two typical grid-side traction converters of CRH series electric multiple unit(EMU)-CRH2 two-level rectifier and CRH5 three-level rectifier. Firstly, the topology structures of two typical rectifiers are analyzed. Then SPWM modulation method, transient direct current control strategy, carrier phase-shift and multiple rectification technique are introduced. Finally, PSCAD simulation model is established. The simulation under different working conditions shows that grid-side traction converter of CRH EMU has the characteristics of low harmonic content, high power factor, stable DC voltage and good dynamic response.
\end{abstract}

\section{Introduction}

Electrified railway has excellent performance compared with other means of transportation ${ }^{[1]}$. In recent years, China has speeded up the construction of high-speed railway. By the end of 2015, China have built high-speed railway about 17,000 kilometers, which accounts for more than 60 percent of the world's high-speed railway mileage. By 2020, operating mileage of high-speed railway in China may go up to 30,000 kilometers, and double track rate and electrified rate are due to reach 50 percent and 60 percent ${ }^{[2,3]}$.

At present, China's high-speed railway electric locomotives are CRH EMU, including CRH1, CRH2, CRH3, CRH5 four types. CRH EMU are AC-DC-AC locomotives which have good operating performance and traction characteristics of high starting power, a wide range of power conditioning, easy maintenance and so on. The above characteristics are advantageous to the high speed and heavy load operation of railway transportation. Because grid-side traction converters of CRH EMU adopt four-quadrant rectifier with full-control power electric devices and PWM control method $^{[4,5,6,7]}$, the power factor of the electric locomotives is high which can be close to 1 and the low order characteristic harmonic content is low ${ }^{[8,9]}$. The intermediate DC part has a large support capacitor. The high order harmonic generated by inverter is weakened by the middle loop and only a small part is fed back into the power grid. Therefore, the harmonic current of the traction condition is mainly produced by grid-side traction converter. So the harmonic characteristics of CRH EMU can be obtained through research on grid-side traction converter.

Although various types of electric locomotives differ from each other, grid-side traction converters of CRH EMU are all four-quadrant PWM rectifier, among which CRH2 EMU use three-level rectifier and CRH1, CRH3 and CRH5 use two-level rectifier ${ }^{[10,11,12,13]}$. Therefore, harmonic characteristics of CRH EMU can be obtained by the research on the above two topologies of rectifier. This paper established PSCAD simulation model of three-level rectifier of CRH2 and two-level rectifier of CRH5, and studied the characteristics.

\section{Grid-side traction converters of CRH2 and CRH5 EMU}

The grid-side traction converter of CRH2 EMU adopts the topology of the three-level four-quadrant of the Neutral-Point-Clamped structure. Its output waveform is more close to the sine wave compared with the two-level structure. 
The grid-side traction converter of CRH5 EMU is two parallel two-level PWM rectifiers. Carrier phase-shift and multiple rectification technique are applied to improve the system equivalent switching frequency, decrease harmonic content and achieve high output power. The main circuits of the grid-side traction converters of CRH2 and CRH5 are shown in Fig. 1.

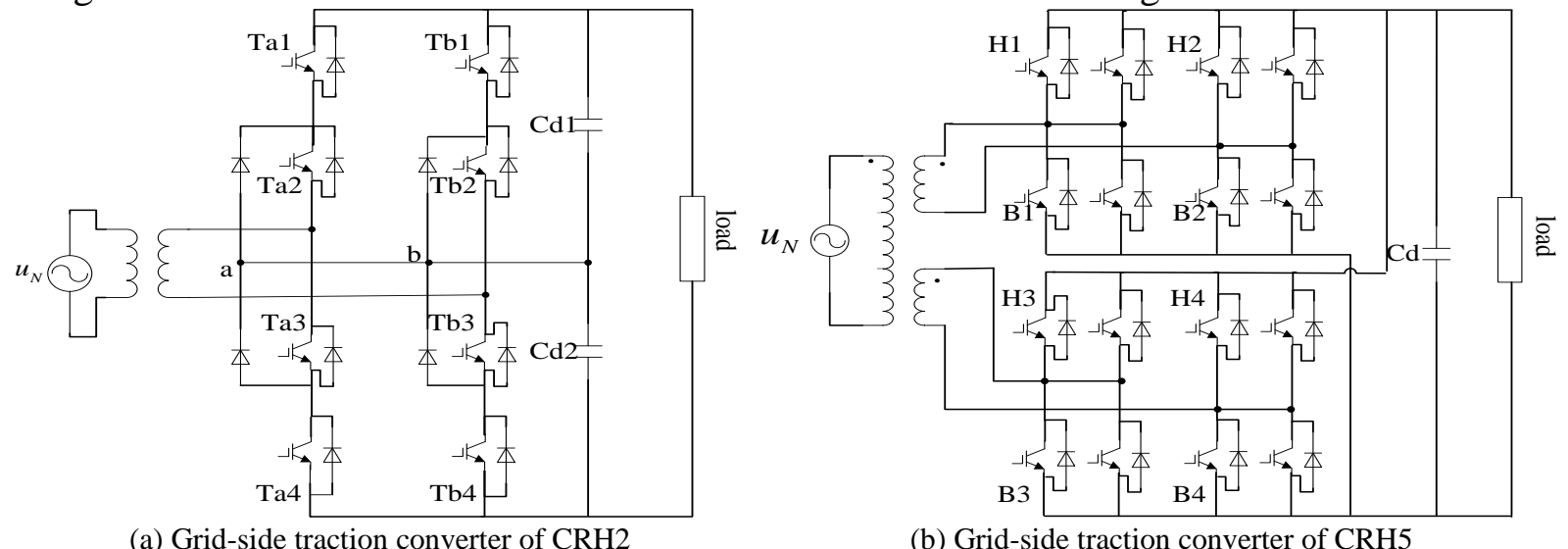

(a) Grid-side traction converter of CRH2

(b) Grid-side traction converter of CRH5

Fig. 1 Grid-side traction converters of CRH2 and CRH5

The main circuit of CRH2 EMU includes two bridge arms, which is composed of four diodes anti-paralleled with IGBTs. The equivalent resistance and equivalent leakage reactance of the grid-side transformer are $R_{N}$ and $L_{N}$. Its equivalent circuit is shown in Fig. 2.

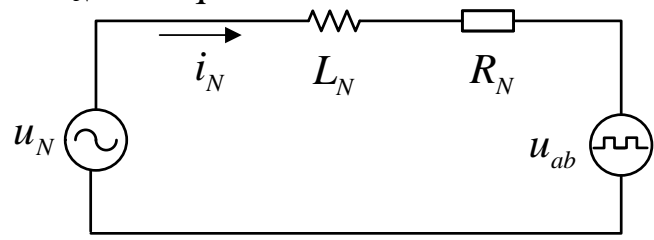

Fig. 2 The equivalent circuit of main circuit of CRH2 EMU

The grid-side traction converter of CRH2 EMU currently adopts SPWM modulation method and transient direct current control strategy. Compared with other control strategies, the advantage of this method is shown as follows: good dynamic response, power factor close to 1, etc. The control strategy can be expressed by the following mathematical model:

$$
\left\{\begin{array}{l}
I_{N 1}^{*}=K_{p}\left(U_{d c}^{*}-U_{d c}\right)+1 / T_{i} \int\left(U_{d c}^{*}-U_{d c}\right) d t \\
I_{N 2}^{*}=I_{d c} U_{d c} / U_{N} \\
I_{N}^{*}=I_{N 1}^{*}+I_{N 2}^{*} \\
u_{s}(t)=u_{N}(\mathrm{t})-\left(I_{N}^{*} R_{N} \sin \omega t+\omega L_{N} I_{N}^{*} \cos \omega t\right)-K\left(I_{N}^{*} \sin \omega t-i_{N}(t)\right)
\end{array}\right.
$$

$K_{p}$ and $T_{i}$ in the formula are the parameters of the PI regulator; and $K$ is the coefficient of the proportional amplifier; $I_{d c}$ and $U_{d c}$ are current and voltage of the intermediate DC side; $u_{N}(\mathrm{t})$ and $U_{N}$ are the instantaneous value and the effective value of the grid-side voltage; $U_{d c}^{*}$ is the given value of DC side; $i_{N}(\mathrm{t})$ is the instantaneous value of the grid-side current. The system block diagram of transient current control is shown in Fig. 3.

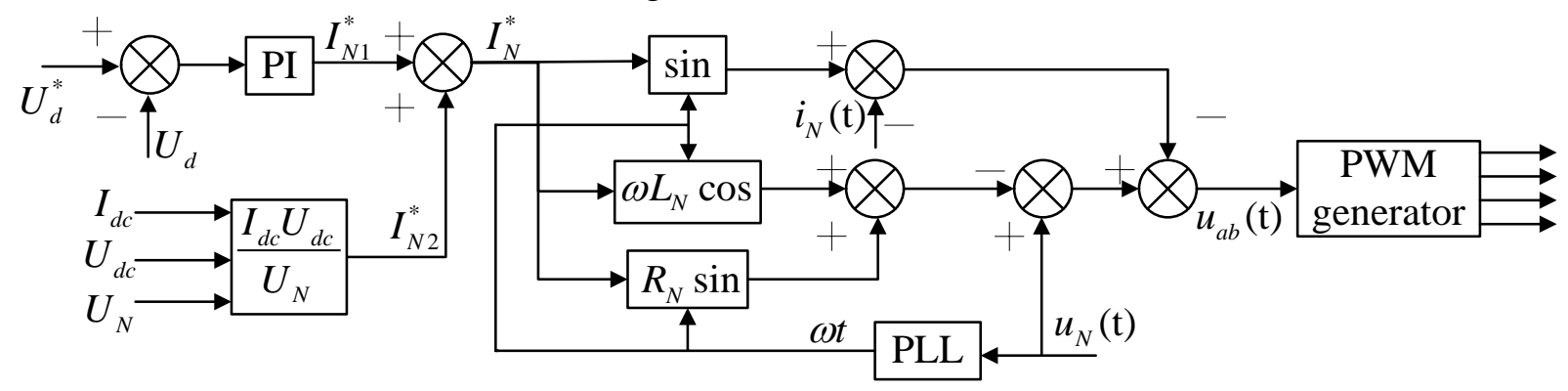

Fig. 3 The system block diagram of transient current control

As in CRH2, grid-side traction converter of CRH5 also adopts SPWM modulation method and transient direct current control strategy. Because multiple rectification technique is applied in CRH5, 
carrier phase-shift technique should be taken into consideration in the control circuit.

Carrier phase-shift technique means that in $N$-multiple rectifier the common sine modulation wave is used and the phase of the triangular carrier signal in rectifier lags $\pi / N$ degrees to generate the pulse signal of each power electric switch. In CRH5 EMU, triangular carrier signal lags 90 degrees in phase.

\section{Analysis on the simulation result}

The PSCAD simulation models of grid-side traction converter of CRH2 and CRH5 EMU are established. The simulation parameters of CRH2 and CRH5 EMU are set as in Table 1.

Table 1 The parameters of CRH2 and CRH5 EMU

\begin{tabular}{|c|c|c|c|c|c|c|c|}
\hline \multirow[b]{2}{*}{$\begin{array}{l}\text { EMU } \\
\text { type }\end{array}$} & \multicolumn{2}{|c|}{$\begin{array}{c}\text { Parameters of traction } \\
\text { transformer }\end{array}$} & \multirow[b]{2}{*}{$\begin{array}{c}\text { Support } \\
\text { capacitor } \\
\text { of DC side } \\
(\mathrm{mF})\end{array}$} & \multirow[b]{2}{*}{$\begin{array}{c}\text { Rated } \\
\text { voltage } \\
\text { of DC } \\
\text { circuit } \\
(\mathrm{V})\end{array}$} & \multirow[b]{2}{*}{$\begin{array}{l}\text { Rated } \\
\text { power } \\
\text { of DC } \\
\text { circuit } \\
(\mathrm{kW})\end{array}$} & \multicolumn{2}{|c|}{$\begin{array}{c}\text { Equivalent } \\
\text { resistance }(\Omega)\end{array}$} \\
\hline & $\begin{array}{c}\text { Effective } \\
\text { value of } \\
\text { primary side } \\
\text { voltage }(\mathrm{kV})\end{array}$ & $\begin{array}{l}\text { Effective } \\
\text { value of } \\
\text { secondary } \\
\text { side } \\
\text { voltage }(V)\end{array}$ & & & & $0 \sim 1 \mathrm{~s}$ & $1 \sim 2 s$ \\
\hline CRH2 & 25 & 1500 & 22 & 3000 & 1296 & 6.9 & 10.4 \\
\hline CRH5 & 25 & 1770 & 9.01 & 3600 & 1751 & 7.4 & 11.1 \\
\hline
\end{tabular}

The equivalent load resistance is determined by the output power of DC circuit $R=U^{2} / P$. The equivalent resistance is set to 1.5 times of the original value at $1 \mathrm{~s}$ as in Table 1 to obtain the dynamic response and the harmonic characteristics of the rectifier in different load conditions. The simulation result is shown in Fig. 4. (In Fig. 4, $\mathrm{uN}$ and iN are grid-side voltage and current.)

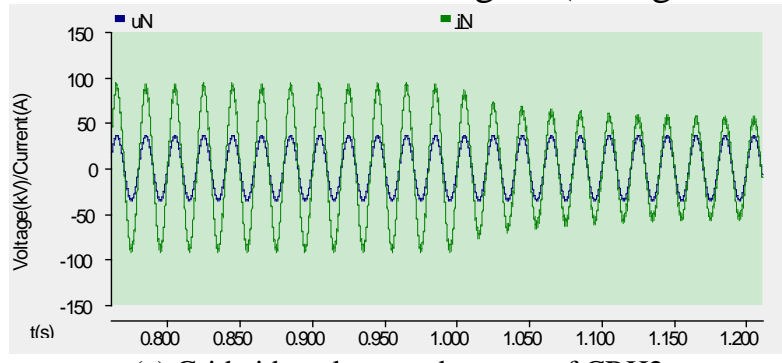

(a) Grid-side voltage and current of CRH2

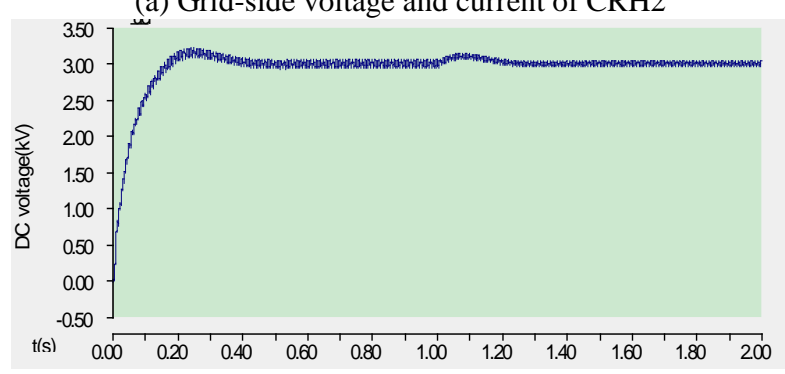

(c) DC voltage of CRH2

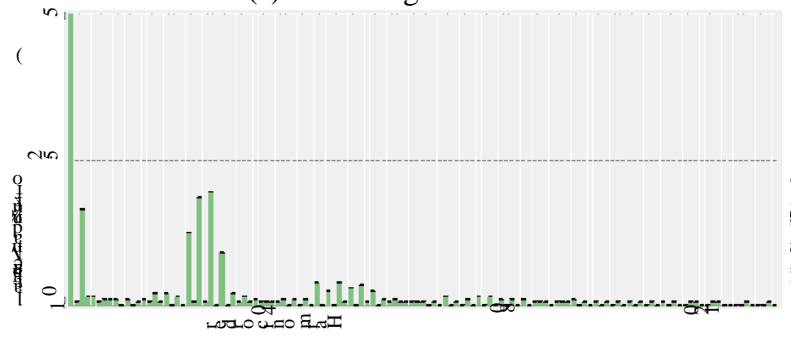

(e) Harmonic distribution of CRH2

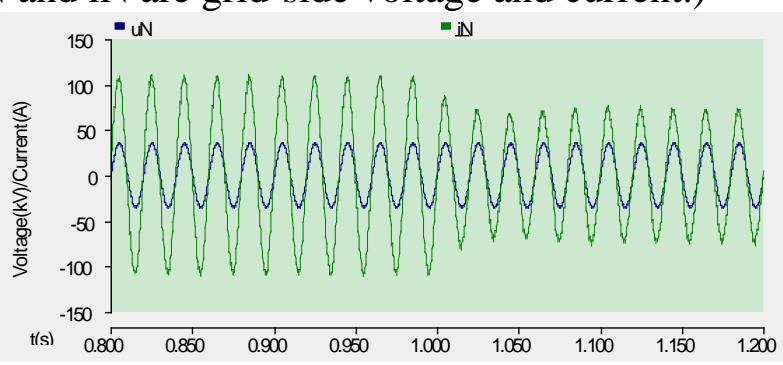

(b) Grid-side voltage and current of CRH5

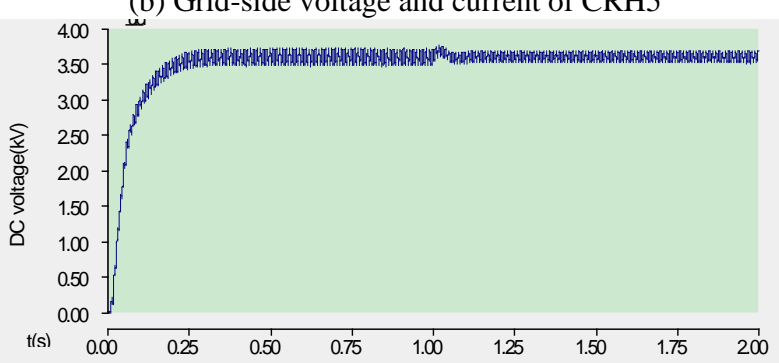

(d) DC voltage of CRH5

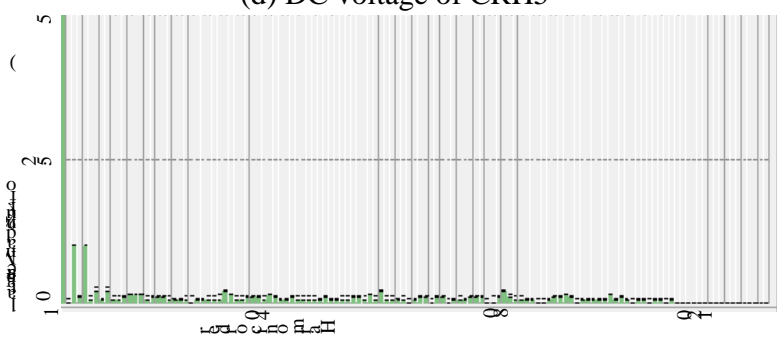

(f) Harmonic distribution of CRH5

Fig. 4 The simulation result

According to the simulation result, the characteristic of grid-side traction converter of CRH EMU can be obtained:

(1) The power factor is high and it can reach more than 0.99 under different load conditions. 
(2) THD of grid-side current is different under different load conditions. In the simulation, THD of $\mathrm{CRH} 2$ changed from 3.68\% to 5.85\% and THD of CRH5 changed from $1.68 \%$ to 3.35\% when load becomes small. So THD is small when load is close to the rated; THD is large when load is small.

(3) Voltage fluctuation of DC side is different under different load conditions. In the simulation, DC voltage fluctuation of CRH2 changed from $3.3 \%(100 \mathrm{~V})$ to $2.0 \%(60 \mathrm{~V})$ and DC voltage fluctuation of CRH5 changed from 5.5\% (200V) to 3.3\% (120V) when load becomes small. DC voltage fluctuate more greatly when load is larger. And all the voltage fluctuation meets the design requirement of CRH EMU.

(4) Rectifiers with different topologies have different harmonic distribution characteristics. In low order harmonic, 3, 5, 7, 9, 11 and other odd harmonic content of CRH5 and CRH2 are high. In high order harmonic, harmonic content of CRH2 near the switching frequence and its multiple is high; harmonic content of CRH5 near the switching frequency and its multiple is not so prominent compared to CRH2. In the higher order harmonic such as the harmonic order over 100, harmonic content is small.

\section{Conclusions}

According to the theoretical analysis and simulation result of two typical grid-side traction converters of CRH EMU, grid-side traction converter of CRH EMU has the characteristics of low harmonic content, high power factor, stable DC voltage and good dynamic response. The characteristics of CRH EMU can be used in the research of power quality problems caused by high speed railway.

\section{References}

[1] Alberto Garcia Alvarez, The Advantages and Advances of Electric Railways [J], IEEE Electrification Magazine, 2014, 2(3):64+60.

[2] Qiu Qian, Research on Electric Railway Power Quality Evaluation Method [D], North China Electric Power University, 2014.

[3] Li Kunpeng, Study of Railway Static Power Conditioner [D], Harbin Institute of Technology, 2013.

[4] Li Yong, CRH1 Type EMU Traction Drive System Simulation Research [D], Southwest Jiaotong University, 2012.

[5] Zhang Zifan, Research on Modeling Simulation and Control Method of Traction Converter of CRH2 EMU[D], North China Electric Power University, 2013.

[6] Yu Danping, Zhou Sheng and Jiang Quanyuan, Research of Direct Torque Control on Traction Drive System of CRH3 EMU [J], Journal of Mechanical and Electrical Engineering, 2010, 27(10):62-67+97.

[7] Zhang Lei, Contrast Analysis of Grid-side Converters of CRH2 and CRH5 Trains [J], Electric Drive Automation, 2015, 37(5):11-15.

[8] Guo Mingfu, Mixed Running Simulation of AC-DC Locomotive and AC-DC-AC Locomotive [D], Southwest Jiaotong University, 2011.

[9] Chen Mingfei, Study on Electrified Railway Power Quality Improvement based Multiple Balance Transformers [D], Hunan University, 2014.

[10] Li Ruirong, Tan Xitang and Xu Chunsheng, Research on the Traction System of CRH1 Electric Multiple Unit [J], Urban Mass Transit, 2012(6):78-83.

[11] Wang Xianbin and Jin Jun, Simulation and Harmonic Analysis of the CRH2 Three-level PWM 
Rectifier [J], The World of Inverters, 2015(6):49-52.

[12] Jiang Dongjie, Traction Drive System of CRH3 EMUs, Railway Locomotive and Car [J], 2008(S1):95-99.

[13] Xiong Shengyan, The Study of the Traction Converter in Electrical Multiple Units of CRH5 [D], Southwest Jiaotong University, 2013. 